\title{
Trayectorias de la periurbanización en Morelia, México: segregación espacial desde un enfoque relacional
}

\author{
Trajectories of peri-urbanization in Morelia, México: spatial segregation from a relational focus
}

\author{
Norma Rodríguez ${ }^{1}$, Antonio Vieyra ${ }^{1}$, Yadira Méndez-Lemus ${ }^{1}$, Rodrigo Hidalgo \\ Dattwyler ${ }^{2}$, Voltaire Alvarado Peterson ${ }^{3}$ y Jesús Rodríguez ${ }^{4}$ \\ ${ }^{1}$ Centro de Investigaciones en Geografía Ambiental, Universidad Nacional Autónoma de México, México \\ ${ }^{2}$ Instituto de Geografía, Pontificia Universidad Católica de Chile, Santiago, Chile \\ ${ }^{3}$ Escuela de Geografía, Universidad Academia de Humanismo Cristiano, Santiago, Chile \\ ${ }^{4}$ Universidad de Guadalajara, Guadalajara, México \\ valvaradop@docentes.academia.cl
}

\begin{abstract}
Resumen
La cuestión de la segregación espacial tiene en el periurbano una faceta diferenciada respecto a otras dimensiones del hábitat urbano-rural. El caso de Morelia, México, expone diferentes situaciones de tensión entre el avance inmobiliario sobre zonas rurales y la perspectiva relacional de las comunidades originarias. La metodología del presente trabajo recoge entrevistas y un archivo fotográfico; ambos antecedentes permiten discutir la actual situación del periurbano latinoamericano y los efectos del avance territorial de la financiarización en la región. En este sentido, tanto la propiedad y la modernidad emergen como estrategias de reproducción de capital en colisión con las relaciones productivas y sociales del área en estudio. Como reflexión de cierre, se propone una perspectiva del derecho a la ciudad que, contradictoriamente, rompe con las bases espaciales y sociales del periurbano en Morelia.
\end{abstract}

Palabras clave: América Latina, Geografía Relacional, periurbano, segregación espacial, neoliberalismo.

\begin{abstract}
The question of spatial segregation has a differentiated facet in the periurban context, related to other dimensions of urban and rural habitat. The case of Morelia, Mexico, exposes different situations of tension between the real estate development over rural areas, and the relational perspective of the original communities. The methodology includes interviews and a photographic archive, bought antecedents allow us to discuss the current situation of peri-urbanization in Latin American and the effects of the territorial advance of the financialization in the region. In this sense, both property and modernity emerge as capital reproduction strategies in relation to the productive and social relations of the study-area. As a final reflection, a perspective about the right to the city is proposed which is opposite to the spatial and social fabric of the Morelia peri-urban area.
\end{abstract}

Keywords: Latin America, neoliberalism, peri-urban, Relational Geography, spatial segregation.

Documento recibido el 11 de noviembre de 2019 y aceptado el 12 de junio de 2020.

La primera autora agradece al Consejo Nacional de Ciencia y Tecnología (CONACYT) por el financiamiento otorgado para realizar estudios de doctorado, proceso del cual deriva la presente investigación.

Cómo citar: Rodríguez, N., Vieyra, A., Méndez-Lemus, Y., Hidalgo Dattwyler, R., Alvarado Peterson, V. y Rodríguez, J. (2020). Trayectorias de la periurbanización en Morelia, México: segregación espacial desde un enfoque relacional. Revista de Urbanismo, 42, 88-104. https://doi.org/10.5354/0717-5051.2020.54924 
La segregación espacial periurbana expresa las transformaciones en las matrices productivas locales, orientándose en la actualidad hacia el capital inmobiliario en América Latina. Nuevas regulaciones y agentes territoriales, junto a la privatización del suelo y una tendencia a la expansión de la propiedad habitacional, entre otras variables, propiciarían este escenario. Las periferias metropolitanas exhiben una inédita restructuración económica, capitalizándose como lugares de reproducción y consumo. El sector inmobiliario, las grandes empresas constructoras y los agentes del capital financiero - bancos y aseguradoras, principalmenteasumen en la actualidad un rol protagónico en la estructura política de lo urbano, incidiendo en la renovación del paisaje periurbano, anterior depósito de la vivienda expoliada destinada a la población más pobre de las ciudades.

El cruce en el presente de estos agentes reflota conceptualmente una idea de segregación latinoamericana, reconocida y debatida a partir de elementos materiales y simbólicos, agrupados históricamente en la manifestación espacial de la exclusión y la desigualdad. Las estructuras de clase y las denominadas soluciones habitacionales se convirtieron en escenarios fértiles en el cruce inmobiliario-productivo, determinando espacialmente la posición desigual de estos agentes (Di Virgilio y Perelman, 2014).

La relevancia por situar estos fenómenos de segregación periurbana se localiza en espacios dinámicos y complejos, donde la habitación se desarrolla con diversidad (Méndez, Vieyra, Güiza-Valverde y Hernández Guerrero, 2016). La configuración territorial neoliberal trastoca las condiciones de emplazamiento, particularmente en los accesos al suelo, servicios e infraestructura. De esta forma, la periurbanización se caracteriza por una expansión física de la ciudad por sobre áreas rurales y de preservación ecológica, sumada a la baja densidad residencial y una topología dependiente de las principales vías de comunicación (Madaleno y Gurovich, 2004; Salazar, Moreira-Muñoz, \& del Río, 2015; Vieyra, 2016).

El objetivo de la presente discusión es analizar desde una perspectiva dialéctica y relacional, las tensiones entre irregularidad, distancia y proximidad derivada de la ocupación residencial de espacios periurbanos. La perspectiva espacial relacional incluye a las estructuras de poder, revelando vivencias, motivaciones y realidades subjetivas de la segregación periurbana. El caso de estudio se encuentra en Morelia, capital del estado de Michoacán en México, ciudad intermedia que ha tenido una dinámica de expansión acelerada, actualmente cuenta 784.776 habitantes. El análisis de entrevistas realizadas posibilita la articulación entre unidades geográficas, como pueblos ejidales, asentamientos irregulares y fraccionamientos cerrados.

El trabajo propone, primero, las tendencias de investigación en segregación espacial neoliberal en América Latina en el periurbano, destacando las contradicciones que presentan su abordaje y sus resultados territoriales en la región. Posteriormente, con la representación de estas cuestiones en la ciudad de Morelia, México, se reconocen evidencias y materialidades en el desarrollo contradictorio de la periurbanización, apuntando a un marco geográfico relacional. Finalmente, se proyectan avances tendientes al estudio del neoliberalismo en tanto condición espacial, evaluando la pertinencia de lo relacional como propuesta en su abordaje.

Nuestra hipótesis plantea que la segregación espacial neoliberal tiene dimensiones específicas y excepcionales en América Latina. Que las zonas de interacción ruralurbana experimenten inéditas prácticas, estrategias y lógicas neoliberales, representa el peso que lo territorial imprime sobre lo identitario, modos de vida históricamente construidos y el sentido de pertenencia a un pasado común. La flexibilidad del periurbano para solucionar el problema de vivienda estatalmente subsidiada, la intervención de los suelos ejidales y comunales originarios, además de la emergencia de asentamientos irregulares originan el cuestionamiento si acaso la modernidad y competitividad que persiguen las ciudades en el contexto actual excluye de entrada otros estilos de vida y otras cosmovisiones sobre el territorio.

\section{La escala relacional de los fenómenos de segregación espacial y la implementación de políticas neoliberales en América Latina}

La presente discusión teórica plantea focalizar a la segregación espacial desde una perspectiva relacional, 
considerando como base la diversidad de factores que inciden en los resultados territoriales de estos procesos.

Desde una perspectiva relacional, los procesos de segregación no pueden comprenderse al margen de las relaciones de poder que operan en diferentes niveles organizacionales en la distribución de bienes y servicios. Las prácticas, estrategias y lógicas a partir de las cuales se estructuran los territorios rurales y urbanos en la actualidad están soportadas en el neoliberalismo como ideología de producción y reproducción del espacio (Hidalgo et al., 2016; Turner, 2017).

La matriz relacional de las ciudades las convirtió en los espacios más importantes de la restructuración económica y socio-espacial del capitalismo, no solo por su potencia en la producción y acumulación de capital, sino además por el amplio esquema de relaciones generadas en ellas. Lo relacional estriba con la cualidad de las ciudades por la aglomeración de las decisiones políticas y económicas, ejercitadas de manera inmediata sobre la producción y el consumo (Gasca, 2013, p. 53). Esto último define lo relacional en un contexto neoliberal como el conjunto de relaciones subjetivas, individuales o colectivas, cuyo desenvolvimiento es afectado por los procesos de transformación estructural. En geografía, lo relacional reconoce las interacciones entre estas subjetividades y las transacciones que dan forma al espacio urbano (Bos \& Jaffe, 2015; Elwood, Lawson, \& Sheppard, 2017). Con la implementación de políticas neoliberales y el desarrollo de transformaciones en el periurbano, estas interacciones estarían situadas en lo relacional, donde lo político del neoliberalismo logra visualizarse en distintos agentes, dando origen a nuevos espacios de segregación (Volochko, 2015).

Por su parte, el margen de lo material tiene un establecimiento teórico conocido. Las políticas de disciplina fiscal, macroeconómica y tributaria establecidas en el Consenso de Washington en 1989 aportaron, sin duda, al desmantelamiento del Estado de bienestar (Martínez y Soto, 2012; Meller, 1991). Como lo plantea Gasca, estas medidas

Fomentaron las formas emergentes de urbanización, refuncionalización y renovación en las ciudades, así como los procesos de distribución del ingreso que ocurren a diferentes velocidades e intensidades privilegiando determinados ámbitos económicos, sectores sociales y lugares en detrimento de otros. (2013, p. 53)

Esta gobernanza global, generada desde el Banco Mundial estuvo focalizada, al menos hasta 2008, en la incorporación de los agentes inmobiliarios a las políticas públicas, que en vivienda ya tenían incorporada a la banca como facilitadores (Banco Mundial, 1994). El traspaso del orden territorial a los gobiernos locales, más el ingreso del mercado hipotecario, al que se agregaba desatendidamente el Estado por la vía de subsidios habitacionales, se amplió como formula efectiva en el marco político regional (Borón, Gambina y Minsburg, 2004). Así, el paquete de ajustes orientado por medio del Consenso de Washington se desagregaba en pequeños territorios y, en contraposición a lo planteado por la crítica más ortodoxa, fortalecía una forma de Estado atomizado en sus capacidades, no disuelto ni absorbido por la iniciativa privada, sino aumentado en su tamaño a dimensiones hasta acá desconocidas (Hidalgo, Alvarado y Santana, 2017a; Maricato, 2013).

Esta relación de subordinación a las nuevas exigencias de los procesos de acumulación capitalista no es variopinta. Como ha sido planteado respecto al "Sur Global" (Brenner, Peck \& Theodore, 2010), se trata más bien de la forma espacial resultante entre lo relacional y lo material en el proceso territorial de transformación neoliberal. No debe sustraerse al Estado que, como estructura, emerge para corregir los excesos de libertad o riesgos morales en la acción de los privados, cuando ha sido necesario. Por ello, debe resaltarse concretamente en las geografías del neoliberalismo que, desde el Consenso de Washington en adelante, el comportamiento de los agentes espaciales se produce bajo el alero de una nueva forma de Estado. En Brasil, el sector inmobiliario formado por grandes empresas constructoras ligadas al capital comercial-industrial, e incorporadas al sector financiero, participa activamente en producción de ciudad, quedando la política urbana en manos de intereses inmobiliarios y financieros privados, mientras que la vivienda subsidiada se ajusta a las directrices internacionales subsidiarias (Klintowitz y Rufino, 2014; Volochko, 2015). Para el caso chileno, como muchos otros en América Latina, la ciudad de Santiago es un ejemplo de exclusión de sectores populares, con su localización en la periferia de la ciudad en función de la producción de viviendas de calidad cuestionable (Álvarez y Cavieres, 
2016; Hidalgo, Urbina, Alvarado y Paulsen-Bilbao, 2017b). Esto ha sostenido un modelo de ciudad altamente segregada y fragmentada a nivel urbano y social (PaulsenEspinoza, 2018).

\section{El periurbano mexicano.}

El caso de México destaca por la introducción de políticas neoliberales acompañadas de intensas campañas ideológicas, sostenidas por los principios de propiedad privada, libre empresa y limitación a la intervención del Estado (Olivera, 2014). Se intensificaron los fenómenos de mercantilización de la tierra convirtiendo al suelo en una mercancía escasa y en algunos casos, eliminándose los programas para la planeación del desarrollo urbano, al mismo tiempo que los organismos de vivienda se convirtieron en entidades de segundo orden (Moreno, Dutrénit y Martin, 2013). Estos cambios, sin duda políticos, han devenido en una forma específica de producción espacial, excluyente de otras formas de habitar el territorio, sus estilos de vida e, incluso, de cosmovisiones (Azuara, 2017).

Los procesos de polarización social experimentados en América Latina, cuya expresión espacial se refleja a partir de la segregación y exclusión son diferenciados y, por tanto, relacionales en sus efectos. Como lo plantea Azuara, el periurbano se opone a las convenciones de la crítica, pues precisa de otras claves para ingresar en su campo de estudio.

la construcción de la diferencia social entre la gente del campo y la ciudad no necesariamente ocurre de manera similar en todas las naciones y en todas las relaciones campo-ciudad que se dan al interior de ellas. Las diferencias dentro de las naciones, en ocasiones, son mayores que entre naciones. (Azuara, 2017, p. 200)

Las transformaciones del periurbano reflejan la asimétrica participación de distintos actores. La intervención local, particularmente aquella en que la política de expansión urbana se coloca por sobre la materialidad del espacio y la acción de los sujetos, supone la instalación de escalas diversificadas y desagregadas de un proceso mayor (Santos, 2014a). El poder territorialmente representado, evidencia las diferencias de estas escalas, a partir de la ocupación y modelación por usos de los periurbanos en la región.
En el periurbano se estructuran nuevos espacios a partir de la mixtura entre las formas urbanas y rurales, constituyéndose en una suerte de túnel del tiempo donde se advierten los escenarios probables para las ciudades del mañana y el lugar del campo en el presente, que tiende a estar supeditado a la sostenibilidad de su matriz productiva. Estas formas -que van desde grandes proyectos inmobiliarios para las elites de las ciudades y fraccionamientos cerrados para las clases medias, hasta colonias populares y pueblos ancestrales entre los que aún se pueden reconocer los de propiedad ejidal y comunal, como en el caso mexicano-, inciden directamente en este enfrentamiento espacio-temporal en el periurbano.

La condición espacial de lo relacional en el periurbano mexicano propone elementos novedosos para su abordaje, debido a las dinámicas de propiedad que allí se generan (Blomley, 2016; Shelton, Poorthuis, \& Zook , 2015). Los encuentros y desencuentros entre los distintos grupos sociales del periurbano están obligados a competir para preservar estilos de vida, racionalidades económicas y formas tradicionales de uso, las que son contradictorias entre sí y frente a lo que se propone como modernización (Harvey, 2001).

Estas características la multidimensionalidad de los espacios periurbanos. Reconocer las condiciones relacionales de un área en particular, permite discutir las bases más ortodoxas de la segregación y fragmentación espacial que, generalmente, se enmarcan en cuestiones geométricas y no necesariamente del sujeto como agente colectivo en la construcción de nuevas topologías territoriales (Inostroza, 2017; Ortiz, y Escolano, 2013). De ahí que los fenómenos de privatización, desregulación y pérdida de la función social de la propiedad, así como la imposición de la propiedad privada como única forma garante de derechos sobre bienes inmuebles, tiende a ser un conjunto recurrente de perspectivas sobre el periurbano (Madaleno y Gurovich, 2004).

Estas inserciones sobre los espacios periurbanos son espejo de lo que acontece en la región, donde la modernización de las formas de explotación del suelo, derivaron hacia el ingreso del sector inmobiliario en los procesos de formulación e implementación de políticas urbanas, mutando las áreas no urbanas en híbridos 
espaciales, carentes de regulación y sometidos a una elasticidad de usos todavía indeterminada (Turner, 2017). De esta manera, fueron incluidos en la gestión y gobernanza periurbana supeditados a los gobiernos centrales, aprovechando su capacidad de intervención y cambio (Springer, 2012).

Es importante destacar las estrategias de loteo y atomización de la cual se sirven los agentes privados, toda vez que el Estado regula y sanciona los espacios para orientar su explotación hacia determinados proyectos de ciudad y entorno. Desde aquí, los fenómenos de segregación espacial en un nuevo territorio avanzan hacia la consolidación de prácticas y modos de vida rurales. Esta gestión de la gobernanza, definida como la capacidad de eficiencia-eficacia de los agentes y estructuras en el marco de una coyuntura, se ejemplifica en la tenacidad de los privados en la región respecto al modelamiento del periurbano.

Una de las características de esta gobernanza periurbana está en la hibridez de sus resultados. La búsqueda de una identidad local abre una gama de mecanismos de control social, amparados en lo normativo (Harvey, 2001). Ante ello emergen rugosidades que alteran la base del periurbano, como la financiarización de la economía que, si bien se ha sostenido que sería la forma contemporánea de superación de las crisis del capitalismo, no se tiene certeza efectiva de los ciclos que desarrollan los productos financieros que solventan la producción capitalista contemporánea (Christophers, 2016; Springer, 2011). El largo trayecto que caminó con mayor fuerza desde la desregulación promovida en la década de 1970, impulsada con las medidas del Consenso de Washington en la década de 1980, prepararon un nuevo régimen de acumulación del capitalismo, el que se habría financiarizado y refinanciarizado en reiteradas ocasiones, incluso con posterioridad a la última megacrisis de 2008 (Springer, 2015; Volochko, 2015).

\section{La cuestión normativa y el periurbano}

La jerarquización normativa de los espacios urbanos y su relación con el mercado financiero refleja la interacción público-privada en la definición de nuevas territorialidades, dejando al neoliberalismo como una ideología más factual que real. Estos supuestos instalan metas de competitividad entre las ciudades, las que se preparan en concomitancia con los agentes que participan de ella para conquistar a la inversión y producir políticas dinámicas (Maricato, 2013). En este campo, los cambios legales son la mejor herramienta.

En México, por ejemplo, el Estado cumple un papel de facilitador en las diferentes escalas de actuación política. Para 1982, con el argumento de la descentralización, se transfirieren todas las funciones urbanas a los municipios, de manera que estas estructuras, en su mayoría carentes de presupuesto y capacidades técnicas, quedan como responsables de la planeación y zonificación al autorizar la construcción de fraccionamientos al sector inmobiliario. En el reporte que el gobierno mexicano presentó al programa ONU-Hábitat III en 2016, se destacaron los avances significativos en cuanto a la importancia que reviste la vivienda como industria en la economía del país. En dicha instancia se valoró la posición de los desarrollos e inversión residencial como actividad estratégica para el desarrollo económico y la generación de empleos, planteándose la necesidad de incentivos normativos y tributarios apropiados para el sector inmobiliario, como medio para lograr la construcción de ciudades equitativas y justas (Gobierno de México, 2016).

Estos incentivos normativos y tributarios para la actividad inmobiliaria se han intensificado, ampliándose las superficies de los programas urbanos y el volumen de edificación de viviendas. La Ley General de Asentamientos Humanos de 1976, que favoreciera los intereses urbanos y políticos de la oligarquía mexicana, fue expuesta a cambios relevantes (Ramírez, 1989). Las modificaciones al artículo 27 constitucional en 1992, una nueva Ley Agraria y otra Ley General de Asentamientos Humanos en 1993, colocaron a disposición del mercado las tierras de los núcleos ejidales, que antes eran inalienables, imprescriptibles e inembargables (Pradilla, 1994). Estas acciones abrieron el nicho de negocios para el sector inmobiliario en los límites de las ciudades, estimulando la fractura de los pueblos originarios (ejidos y comunidades) que se vieron inmersos en la construcción masiva de vivienda para grupos sociales diferenciados.

La ruta política de estos ejercicios de gobernanza global se localiza, también, en las acciones del Fondo Monetario Internacional, el Banco Mundial y la Organización Mundial de Comercio que, entre 1970 y 1990, establecieron nuevas formas de gestionar las 
ciudades. A estas se suman los negocios especulativos y el desmantelamiento de mecanismos para la redistribución de la riqueza socialmente producida, aportando a nuevas formas de urbanización segregada (Olivera, 2014).

Para el objetivo de este manuscrito, las cuestiones expuestas en esta sección decantan en una ciudad con cualidades y vocaciones periurbanas. El caso de Morelia destaca por la constatación de una sostenida modelación espacial de medidas neoliberales, que propiciaron el encarecimiento del suelo y la proliferación en el periurbano de asentamientos precarios y conjuntos habitacionales cerrados. De estas situaciones se derivaron otras, como la generación de nuevas centralidades, formas de exclusión y desigualdad (Poncela, Vieyra y Méndez, 2015). Los habitantes de fraccionamientos cerrados, proyectos inmobiliarios de élite, asentamientos irregulares, pueblos ejidales y comunales, ocupan un espacio específico vecinal en que difícilmente establecen relaciones de comunidad, dadas las barreras físicas, sociales, culturales e identitarias, materializando otra forma de escala relacional para el análisis de la segregación periurbana.

En la siguiente sección se trabajará con el modelado de las cuestiones planteadas, recurriendo a las elaboraciones conceptuales frente al contexto actual de la producción de capital y las dinámicas de segregación en espacios latinoamericanos únicos, como es el caso de Morelia, México.

\section{Metodología de entrevistas y levantamiento cartográfico}

Nuestro caso de estudio se ubica en Morelia capital del estado de Michoacán, en México, esta ciudad se localiza en el centro-occidente del país y cuenta con catorce jefaturas de tenencia. En la encuesta intercensal de 2015 el municipio registró una población de 784.776 habitantes, cifra que convierte a Morelia en ciudad intermedia, según la clasificación emitida por la Organización Mundial de Ciudades y Gobiernos Locales Unidos. El poniente de dicha ciudad presenta diversos usos de suelo dedicados a la explotación de recursos diversos, vinculados a una matriz productiva rural, con reciente ascenso de espacios urbanizados. Estas características explican, en parte, la tensión entre las orientaciones territoriales de sus habitantes e intereses de ocupación territorial.

Para este marco se definió un tipo de clasificación espacial periurbana, a partir de un ejercicio de observación in visu, técnica que permite reconocer elementos del paisaje a través de la mirada del observador. En este caso el ejercicio se realizó con imágenes satelitales y cartografía del Programa de Desarrollo Urbano del Centro de Población de Morelia de 2010 (PDUCPM) y sus adecuaciones 2012, clave E-02, 2/3 con el fin de determinar los usos de suelo y los principales nodos de interacción rural-urbano. El trazado poligonal obedece al PDUCPM y las coberturas vectoriales disponibles en el Registro Agrario Nacional a partir de la interacción de suelo urbano y rural para $2017^{1}$.

El procesamiento y análisis de la información espacial se desarrolló en la plataforma ArcGIS 10.4, con el fin de identificar y delimitar la ocupación del suelo a partir de tres procesos: 1) análisis de percepción remota a partir del método de clasificación supervisada, calibrada con observaciones de campo (García y Mas, 2008); 2) los datos obtenidos fueron procesados a partir de una prueba de máxima verosimilitud con base en imágenes de satélite del sensor Sentinel 2A, del 01 de marzo de 2017; 3) se combinaron las bandas 8,4 y 3 mediante la composición RGB en falso color, identificándose ocho categorías correspondientes a áreas urbanas (diferentes densidades y equipamiento), cultivos de riego, cultivo temporal, suelo desnudo, pastizal, bosque, vegetación inducida (principalmente árboles ornamentales) y agua. Esta clasificación requirió de la elaboración de 225 campos de entrenamiento, distribuidos uniformemente sobre la imagen combinada. Finalmente, estos ejercicios arrojaron como resultado una clasificación periurbana concentrada en tres áreas: urbanas, urbanizables y de uso agropecuario.

El segundo proceso consistió en la redefinición y delimitación de espacios en campo para la integración de

\footnotetext{
1 Disponible en http://www.ran.gob.mx/ran/index.php/sistemas-deconsulta/sistema-de-informacion-geoespacial
} 
elementos principales de interés, como pueblos ejidales, fraccionamientos habitacionales de grandes dimensiones, asentamientos irregulares y áreas de protección agrícola, pecuaria y ambiental, advirtiéndose fenómenos de segregación periurbana con base topológica entre puntos (ver Figura 1). El trazado de estas líneas permitió analizar la relación entre proximidad y distancia; la primera marcada por cuestiones culturales e identitarias, mientras que la segunda por la distancia en kilómetros de un asentamiento a otro ${ }^{2}$.

\section{Figura 1}

Segregación espacial y usos de suelo en el periurbano de Morelia
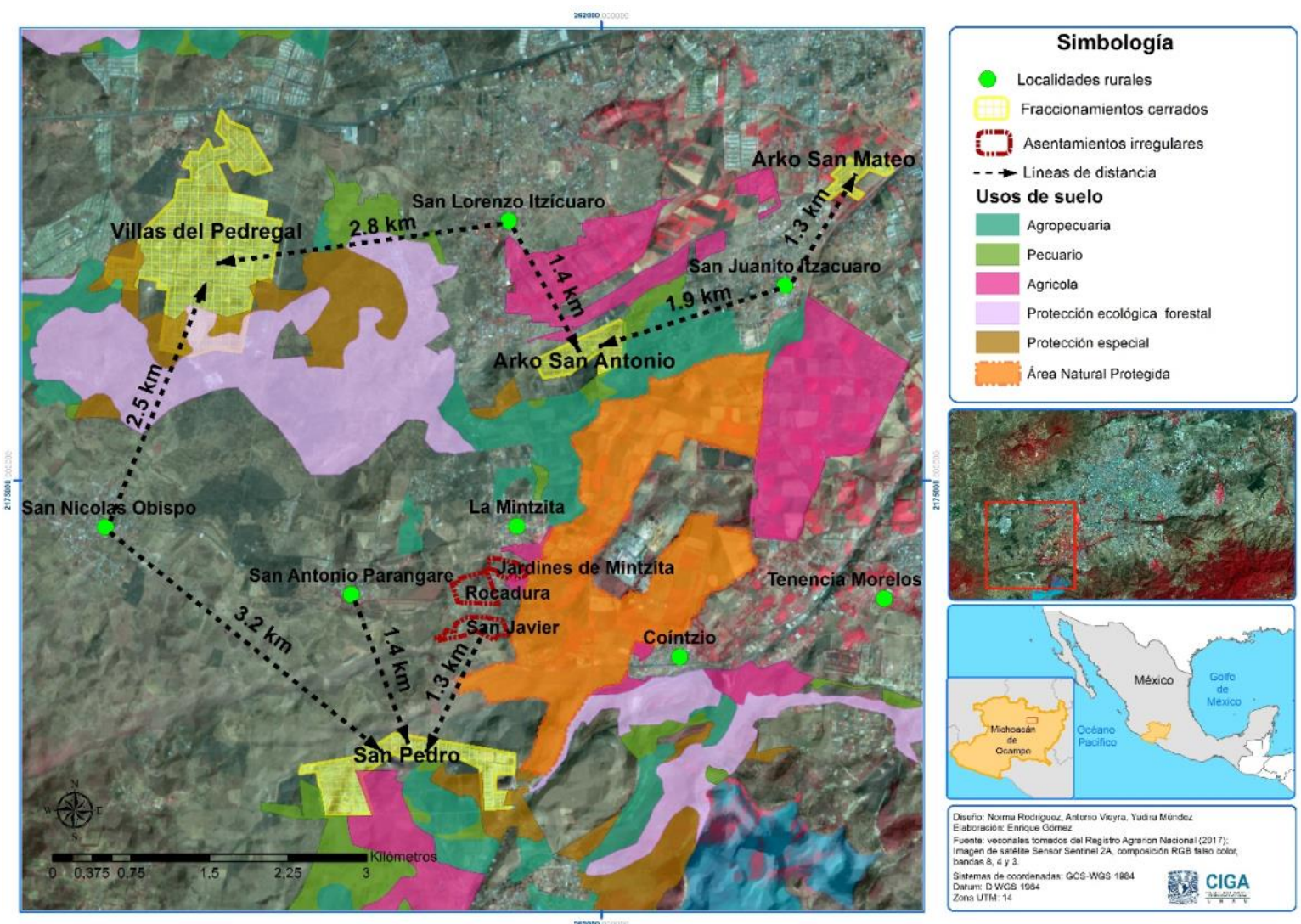

Fuente: elaboración de autores con base a imagen satelital y vectoriales Registro Agrario Nacional (2017).

\footnotetext{
${ }^{2}$ Para determinar la distancia entre los puntos se utilizó la herramienta

"distancia de punto" del software ArcGis 10.4.
} 
La última actividad correspondió a entrevistas enfocadas a levantar la perspectiva relacional, trasversal y analítica respecto a los anteriores ejercicios, se realizaron 12 entrevistas con habitantes de la zona de estudio. Esto permitió reconocer la percepción de ejidatarios y fraccionadores irregulares en los fenómenos de interacción urbano-rural, atendiendo las cuestiones de distancia y proximidad. Con una metodología semiestructurada, las entrevistas indagan temas generales, como los procesos de integración de tierras ejidales al crecimiento urbano -reforma al artículo 27 constitucional-; superficie de tierras del ejido vendidas para el crecimiento urbano; cambios de uso de suelo ventajas y desventajas para el sector rural-; integración/segregación urbano-rural; programas de apoyo al campo; suficiencia o insuficiencia del marco jurídico; y por último, políticas y programas urbanorurales.

Los actores con los cuales realizaron entrevistas a profundidad se encuentran en un rango etario de entre 40 y 80 años, la muestra se realizó con los representantes de los pueblos ejidales y de colonias irregulares estudiadas. Los resultados de las entrevistas se presentan en formato de extractos que proponen fundamentar una escala relacional en las transacciones entre intereses $y$ percepciones espaciales en el periurbano, con el concurso de variables modelables, pero con una robusta fijación en lo intersubjetivo, como hoja de ruta en el análisis de estos espacios.

\section{Fenómenos de segregación espacial en el periurbano de la ciudad de Morelia}

En las últimas tres décadas Morelia ha presentado una dinámica de expansión acelerada, su crecimiento poblacional no corresponde con la expansión desproporcionada de la superficie urbana, que ha tenido como consecuencia la caída de la densidad a través de los años (ver Tabla 1).

Este proceso expansivo, liderado por el sector inmobiliario y amparado en las políticas neoliberales, originó un escenario de segregación en el poniente de Morelia por la construcción de fraccionamientos de grandes dimensiones para las clases medias, como Villas del Pedregal (ver Figura 2) , Arko San Pedro (ver Figura 3)
Arko San Antonio y Arko San Mateo, con la presencia en su entorno inmediato de los ejidos de San Juanito Itzícuaro, San Lorenzo Itzícuaro, San Nicolás Obispo, La Mintzita, San Antonio Parangare, Cointzio y Tenencia Morelos. Estas localidades de origen rural, en algunos casos pueblos ancestrales que son alcanzados por la mancha urbana y que pasan a formar parte de un espacio segregado junto con asentamientos irregulares como Rocadura, San Javier y Jardines de la Mintzita (ver Figura 1).

Tabla 1

Crecimiento demográfico y físico de Morelia

\begin{tabular}{lrrrr}
\hline Año & $\mathbf{1 9 8 0}$ & $\mathbf{1 9 9 0}$ & $\mathbf{2 0 0 0}$ & $\mathbf{2 0 1 0}$ \\
\hline Población & 257.209 & 428.486 & 549.996 & 597.511 \\
Superficie (ha) & $1.898,6$ & $2.216,7$ & 9.227 & $20.120,8$ \\
Incremento (ha) & 531,0 & 318,1 & $7.010,3$ & $10.893,8$ \\
Densidad (hab/ha) & 135,47 & 193,29 & 59,33 & 36,24 \\
\hline
\end{tabular}

Fuente: Elaboración propia con datos de los programas de desarrollo urbano de Morelia.

La entrada al mercado inmobiliario de tierras ejidales se concretó en el gobierno de Salinas de Gortari (19881994), administración que aceleró y profundizó las reformas estructurales de la economía a través de cambios institucionales que en mediano plazo se reflejarían en una división y ocupación diferenciada del espacio, según las características de los grupos sociales que en el habitan (Gasca, 2013, p. 32). La aparición de formas de crecimiento habitacional discontinuas respecto a la ciudad, tanto a favor de centros urbanos menores como de ocupación rural, se justificó en los discursos oficiales con el argumento del déficit habitacional, transformando el patrón tradicional de segregación con el surgimiento de nuevas formas urbanas vinculadas a la privatización y mercantilización del territorio (ver Figura 2, 3 y 4 ). Las familias se mudaron a la periferia para tener acceso a soluciones habitacionales público-privadas y el sector inmobiliario las insertó en una nueva cotidianidad al incluirlas al consumo de productos inmobiliarios, muchas veces carentes de servicios, infraestructura y equipamientos adecuados (Volochko, 2015). 


\section{Figura 2}

Fraccionamiento cerrado Villas del Pedregal

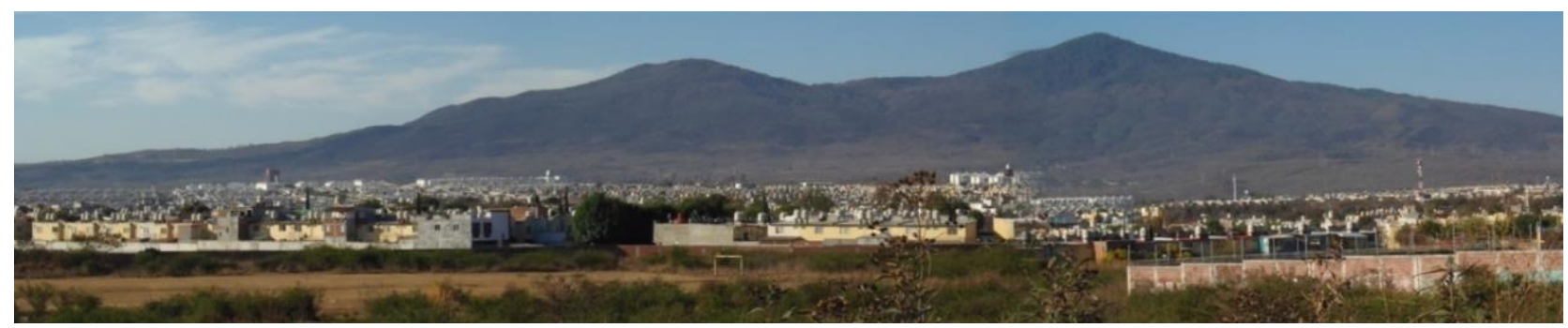

Fuente: archivo de autores, febrero de 2019.

\section{Figura 3}

\section{Fraccionamiento cerrado Arko San Pedro}

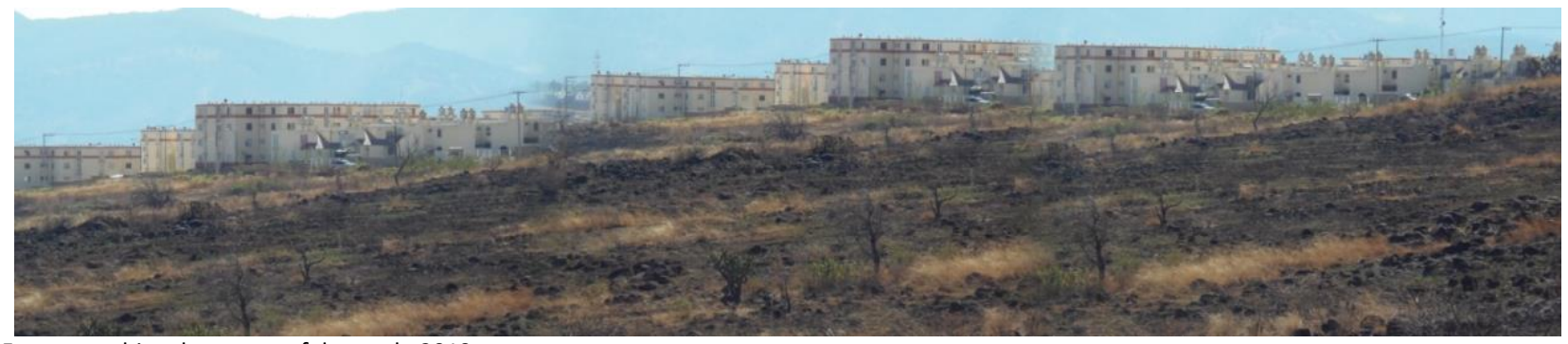

Fuente: archivo de autores, febrero de 2019

Los fenómenos de segregación adquieren dimensiones distintas en el periurbano, donde la comercialización de tierras es operada por propietarios individuales. Los gobiernos a escala local establecen las condiciones para incentivar la inversión inmobiliaria, relegando funciones de edificación y mejoramiento de vivienda hacia este sector económico (Aguilar, 2001; Ávila, 2014; Rodríguez, 2017).

De esta forma, la planeación periurbana se convierte en un ejercicio entre las concepciones del crecimiento económico y el neoliberalismo urbano, registrándose una escasa interacción social, donde las relaciones humanas están centradas en el uso del tiempo y no en la ocupación del espacio (Lungo, 2005). Esta materialización espacial e ideológica del individualismo trasciende y anula la posibilidad de proyectos habitacionales que promuevan la integración sustancial de diferentes grupos sociales en el espacio (Fernández, 2016).

\section{La experiencia espacial del fraccionamiento}

Las acciones institucionales fomentan la marginación de espacios ocupados por la población empobrecida, condenada a vivir en espacios fragmentados por la especulación utilitaria del suelo. A esto se suma la tendencia de la legislación a reducir la participación del colectivo social, ampliando la intervención del sector privado en los organismos de consulta de las instancias gubernamentales. Similar es la situación de los dispositivos estatuidos como programas de desarrollo urbano, los cuales operan sin realizar las consultas públicas que la ley les mandata, alterando las políticas de ordenamiento territorial y sus objetivos de desarrollo urbano (Congreso Legislativo, 2015). Estas medidas reflejan las relaciones de poder ejercidas sobre el territorio, la dominación del espacio social y la vida cotidiana de grupos sociales como medio para la reproducción capitalista que conlleva la reproducción de nuevos niveles de desigualdad socioespacial (Volochko, 2015). 
La priorización de las decisiones públicas que posibilitan el establecimiento de mecanismos como el dominio pleno, permiten al sector inmobiliario edificar en suelos ejidales de uso forestal o agrícola, en los que existen poblaciones cuyos medios y modos de vida son rurales. Esto las excluye y fomenta la autoexclusión de nuevas formas urbanas que se construyen en su entorno inmediato

No hay integración del ejido con las nuevas colonias y fraccionamientos, a la gente del campo se le ve como si tuviera lepra, como que lo consideran una gente ignorante y lo van relegando, 'yo vivo para acá y tú vives para allá', 'yo tengo mis servicios y allá arregla tú los tuyos'. (entrevista realizada el 19 de agosto de 2017, con el Comisariado Ejidal de San Lorenzo Itzícuaro)

La segregación es parte de la formación de estilos de vida. La reforma al artículo 27 constitucional facilitó el proceso de dispersión de asentamientos humanos con estilos de vida diferentes a los pueblos ejidales, rompiendo los vínculos entre habitantes que se conocían y compartían un pasado común. Santos (2014b), respecto al caso brasileño, señala que la ciudadanía es también rural pero el mercado y el Estado contribuyen a ignorar a este sector, inmerso cada vez más en los procesos de modernización:

Hoy con la difusión de los valores distorsionados de la modernidad, valores que frecuentemente son dados como si fuesen valores urbanos, la red de relaciones antes instalada en la ciudad se extiende a todas partes, con la industrialización de la agricultura y la modernización del campo. Las restricciones que se oponen a una plena realización del individuo y de la vida social están en todas partes. (Santos, 2014b, p. 43)

En la actualidad, estos pueblos asumen una condición de segregación relacional, pues no conocen ni se identifican con los nuevos habitantes emplazados en su entorno inmediato ${ }^{3}$. El elevado precio del suelo detonó la exclusión de quienes no alcanzan sus costos, al mismo tiempo que afecta la localización de nuevas viviendas para grupos de ingresos bajos fuera de la ciudad (Sabatini y Brain, 2008).

Simbólicamente, las bardas perimetrales operan como fronteras entre las nuevas concentraciones de población y los asentamientos rurales, dejando a las casetas de vigilancia en el cierre de toda posibilidad de interacción (ver Figura 4)

\footnotetext{
${ }^{3}$ Entrevista realizada el 29 de agosto de 2017, con el Comisariado Ejidal
} de San Juanito Itzícuaro. 


\section{Figura 4}

\section{Barda perimetral en el periurbano de Morelia}

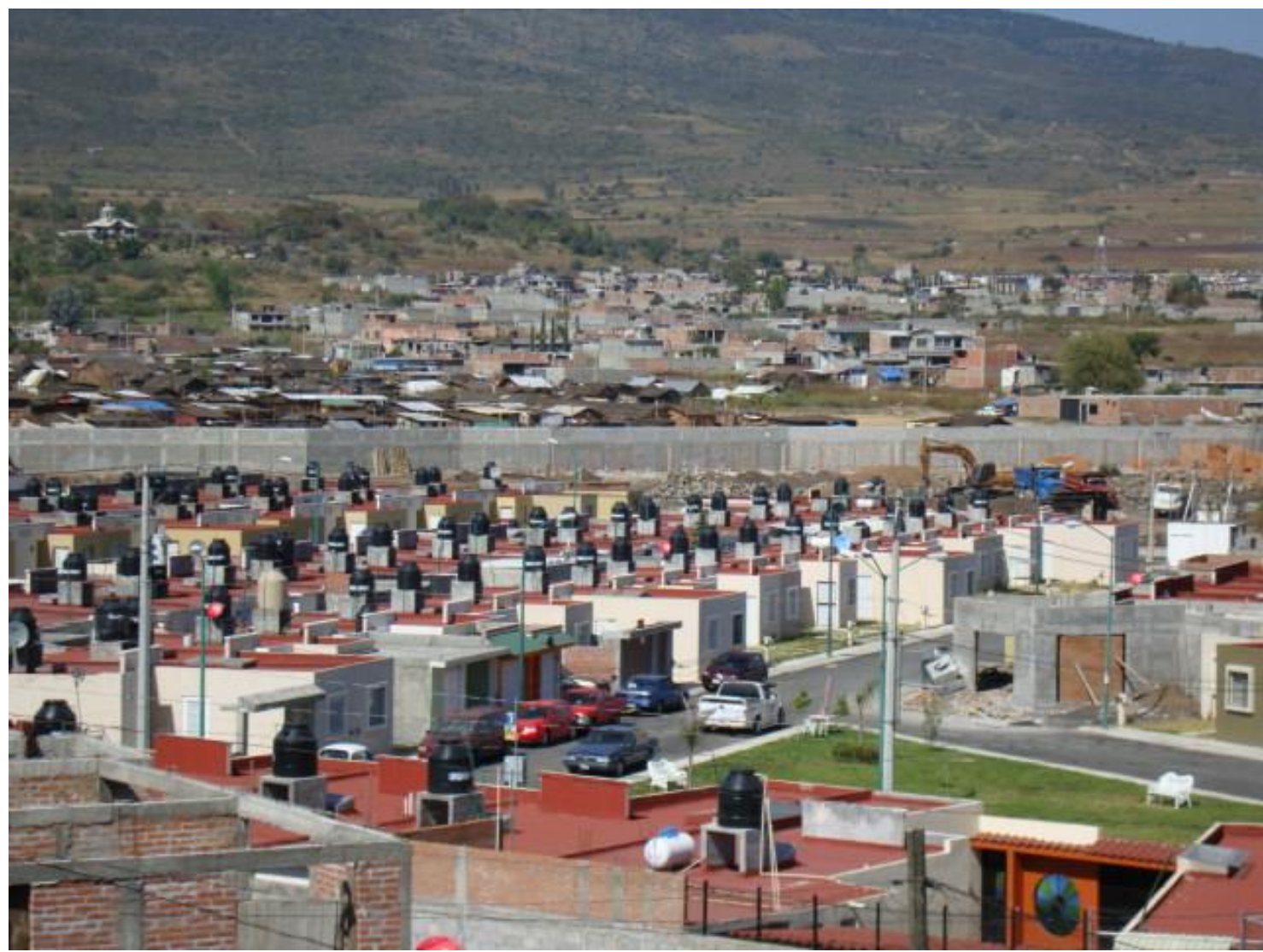

Fuente: archivo Juan Hernández, noviembre de 2009.

Los hombres y mujeres del campo son menos titulares de derechos que la mayoría de los hombres y mujeres de la ciudad (Santos, 2014 b). Esto se aprecia en la pérdida de prácticas esenciales, como el derecho a transitar libremente. Azuara (2017) plantea la importancia de ir a la raíz del problema para no reproducir espacios de desigualdad social que subsuman a los pueblos y comunidades rurales en el entramado urbano.

\section{Competencia y transformación espacial}

La competitividad neoliberal y la innovación de las ciudades posibilitan el despojo a campesinos y la destrucción del espacio natural, entre otros procesos. La política urbana coloca a los derechos de propiedad como base para el desarrollo económico urbano, al mismo tiempo que delimita las zonas metropolitanas. El fomento a la propiedad incentiva la construcción de núcleos de vivienda desvinculados de los sistemas urbanos, donde los pueblos ejidales son relegados a ocupar un espacio cancelado de toda posibilidad de interacción física y social.

Para los pueblos originarios, la degradación social sustenta desventajas que conllevan el aislamiento físico de un nuevo modelo urbano. La flexibilización laboral y la marginalización política de los pobres agudizan los fenómenos de segregación espacial, recurriendo a procesos de urbanización popular, como la invasión ilegal de terrenos, también presentes en Morelia.

Efrén Capiz, reconocido luchador social en la década de los noventa, pretendía establecer un estilo de vida comunitario en tierras ignoradas, que en el pasado pertenecían a la Hacienda los Itzícuaros, en cuya superficie de aproximadamente 40 hectáreas, estableció una zonificación que incluía tierras para el asentamiento, la agricultura comunitaria y para uso pecuario. Con el tiempo, otros grupos ocuparon las tierras de uso agrícola 
y pecuario, formándose tres asentamientos: Rocadura, San Javier y Jardines de la Mintzita (ver figura 1).

Estos grupos, a pesar de tener características socioeconómicas homogéneas, han tenido encuentros y desencuentros en la lucha colectiva por la regularización de sus tierras y la introducción de servicios. La dimensión espacial se antepone, en estos casos, al conjunto complejo de existencias materiales e inmateriales que advierten la importancia de distinguir entre distancia y proximidad espacial.

La proximidad no se limita a una mera definición de las distancias. Tiene que ver con la continuidad física entre personas en una misma extensión, pudiendo crear solidaridad, lazos culturales y, de ese modo, identidad. La continuidad espacial y el régimen de propiedad son elementos determinantes de las funciones espaciales, como la existencia de una superficie de propiedad privada perteneciente a personajes asociados a los círculos políticos del Estado entre los asentamientos de Rocadura y San Javier ${ }^{4}$. Esta segmentación en la escala espacial modificó los aspectos positivos asociados a los fenómenos de segregación, como los emprendimientos para mejorar sus condiciones de vida, formación o defensa de identidades sociales y la energía desplegada por los pobladores en la autoconstrucción de sus viviendas o en el mejoramiento de su barrio, así como la secuencia de metas en el imaginario colectivo:

Lo primero que hicimos fue el comedor pues aquí no había ni qué comer; después, con otro proyecto construimos estos módulos para la clínica naturista, se formaron escuelas, se empezó con una de educación de adultos apoyados por el INEA -Instituto Nacional de Educación para Adultos-. Después alguien dijo que 'no podíamos seguir juntos porque había una franja en medio que no era comunal, entonces no podíamos seguir juntos había algo que nos separaba'. (Entrevista realizada el 18 de julio de 2017 con representante de San Javier)

El cooperativismo y la solidaridad se rompen con la segmentación espacial, produciéndose una

${ }^{4}$ En entrevista representantes de los asentamientos de San Javier y Rocadura, señalan que ahí tiene una casa de descanso el Dr. Rogelio Vallejo hermano del tres veces presidente municipal de Morelia y discontinuidad en las secuencias de metas colectivas. La proximidad de los asentamientos irregulares se deriva del contenido comunicacional, otorgando una percepción más clara de las situaciones personales o de grupo que, junto a la afinidad de destino, económica o cultural, conforman elementos materiales y simbólicos no considerados por la política y planeación urbana (Santos, 2014a). La tenencia ilegal de la tierra, la inobservancia de las normas de uso del suelo y de construcción marcan a muchos barrios pobres como ilegales o irregulares, dejando a la política de regularización como creadora de tensiones, en lugar de ser agencia de resolución y conducción. El reforzamiento de la propiedad privada y el fracaso de políticas para controlar los precios del suelo complejizan el acceso a los pobres a las estructuras residenciales, marginándolos a ocupar espacios con escasez de servicios e infraestructura, lugares que reciben las descargas de aguas negras de las nuevas urbanizaciones:

Las constructoras van arrasando, y cuando se vengan los problemas para sustentar a toda esa gente de agua, ¿a dónde van los drenajes? las aguas negras vienen atravesando las comunidades al aire libre y tenemos registrados veinte niños enfermos por tanta contaminación. (entrevista realizada el 18 de julio de 2017 con la representante de Rocadura)

El problema de aguas negras es generalizado en el poniente de la ciudad. Los manantiales y ríos que tradicionalmente usaban los pueblos rurales son contaminados, sin ser acogidas sus reclamaciones por los organismos públicos. Destinados a proteger a la población, estos acaban por desorientarla con sus clasificaciones incompletas e incomprensibles. En parte, estas discusiones están asociadas a la colisión entre distintas concepciones del desarrollo urbano, las que no han sido adecuadas a las condiciones de cada lugar.

El presidente dice 'hay que urbanizar', pero ¿cómo van a urbanizar?, ¿con atención a qué?, ¿̇a qué tipo de población?, ¿a qué espacio?, eso no está en la ley. En principio, ¿qué está pensando el presidente
Gobernador del Estado Fausto Vallejo, así como Enrique Bautista quien fuera Secretario de Gobierno durante el sexenio de Cárdenas Batel. 
por urbanizar? y nosotros también ¿qué estamos pensando?, no queremos tanto cemento, queremos empedrado, pero esos programas no los contemplan. (Entrevista realizada el 18 de julio de 2017 con representante de San Javier)

\section{El otro en el periurbano relacional}

El derecho a expectativas legítimas plantea considerar como interlocutores a los receptores de las políticas urbanas para generar una planificación urbana justa, situada en criterios de diversidad y equidad. El primero de ellos debate el reconocimiento del 'otro' que tiene derecho a definirse a sí mismo por medio de diferentes manifestaciones urbano-rurales (Paulsen-Espinoza, 2018). El reconocimiento de derechos legales de acceso al suelo no debería ser una medida aislada, sino parte de un proceso político que otorgue una regularización de la propiedad del suelo que propicie la integración. Una política general de control de la segregación, en contextos como el de Morelia, no atiende la diversidad de otredades que allí se cruzan, al sostener un crecimiento urbano disperso por fuera de las identidades de los distintos grupos sociales

No nos sentimos integrados con los nuevos fraccionamientos. Excluidos sí, siempre nos sentiremos, pero no somos los únicos. Sabemos que todas las comunidades están excluidas y nosotros nos identificamos más con los pueblos ejidales. Con los nuevos fraccionamientos a lo mejor conociendo a la gente, pero identificados con ese tipo de población no. 'Sí, estamos marginados, pero no aspiramos [a] ese estilo de vida para nada'. (Entrevista realizada el 18 de julio de 2017 con representante de San Javier)

Estas resistencias, apuntan a la idea de priorizar las acciones y prácticas ciudadanas para construir ciudad desde lo ciudadano y desde lo social, oponiéndose a la destrucción mercantil que privilegia la especulación y la acumulación capitalista (Ramírez, 2017).

La estructura de clases juega un papel central en los fenómenos de segregación. El individualismo utilitarista ha generado espacios sin sentido, donde la cultura de la competencia y la creación de valor asociada al mercado se imponen (Fernández, 2016). La presión permanente sobre las estructuras tradicionales, como resulta en el caso de los entrevistados, termina por imponerse a lo rural y a una cierta urbanización de actividades racionalizadas con un fin determinado. Una relación permanente e inestable, y donde la globalización, localización y fragmentación son términos de una dialéctica que se rehace con frecuencia (Santos, 2014a).

\section{Conclusiones}

Los estudios en el tema de segregación han profundizado en la espacialización diferenciada y en las lógicas de exclusión y desigualdad de manera aislada. Las dimensiones que se refieren a la liberación de los mercados urbanos de suelo y vivienda han sido poco estudiados, así como la exclusión y autoexclusión de la población rural en el periurbano de las ciudades. La inclusión de la intervención del sector inmobiliario en la estructuración de las ciudades es central para evidenciar los procesos de segregación actuales, en los que las políticas de uso de suelo tienen una concepción espacial que pone énfasis en su forma y tamaño, mientras el conjunto complejo que encierra su valor de uso es relegado a un segundo plano.

El enfoque relacional permite enlazar estos procesos, a veces dispersos en el debate científico contemporáneo. La segregación no deja de ser uno de los resultados territoriales entre lo público y lo privado, donde la transacción entre la política y el mercado se diluye en diversas aristas. Por una parte, si bien se atienden las demandas por ciudad, vivienda y acceso a servicios con la expansión hacia el periurbano; también es cierto que las comunidades se fracturan ante la ausencia de mecanismos de participación territorial efectivos. Por otro lado, las disputas por el periurbano inciden en la deformación de los bienes comunes, como el agua o el suelo, entendidos esenciales en la construcción histórica de los derechos en México. Esto último no deja de ser alarmante, pues el fenómeno de la urbanización ejidal no es ajeno a las transgresiones a la norma que consagra a las propiedades colectivas de la tierra como recurso esencial para el desarrollo local (Aguilar, 2001).

Estas relaciones acusan una diferenciación con los procesos de segregación periurbanos en las ciudades de América Latina, los que están estrechamente relacionados con los modelos de ciudad surgidos en el contexto neoliberal de las políticas urbanas. El caso estudiado 
refleja la contraposición entre los espacios tradicionales y los impulsos de modernización que anteponen a la innovación y la competitividad como ejes transversales de un paisaje de desarrollo, que debe alcanzarse a través de la construcción de formas arquitectónicas desvinculadas de los usos tradicionales y modos de vida existentes, que pueden favorecer la proximidad de distintos grupos sociales.

Los resultados del trabajo en Morelia reflejan la urgencia por superar el enfoque de variable única en la construcción de políticas territoriales. La tendencia verificada en el caso de estudio señala que la expansión urbana atraviesa las subjetividades, cuestionando sus derechos y formas de vida que contribuyen en una escala relacional a una versión de la segregación por sobre las barreras materiales que la justifican. Esta es la base de la hipótesis planteada, donde la diferenciación como ejercicio relacional en el análisis espacial, expone la unidireccionalidad en la elaboración de políticas basadas en el crecimiento residencial. La ausencia de un enfoque relacional en la construcción de respuestas espaciales integradas a problemas mayores, como los exhiben los resultados trabajados, resalta la pertinencia de nuevas políticas urbanas con papel decisorio y participación desde el reconocimiento a la diversidad, sea a través de las normas jurídicas o de los procesos de transformación a los usos del suelo.

Para lograr una producción social del espacio las políticas urbanas deben enfocarse a fortalecer los aspectos positivos de los fenómenos de segregación, como los emprendimientos de los grupos pobres para mejorar sus condiciones de vida y en mitigar la evolución de los aspectos negativos relacionados con la elitización y monopolización de la exclusividad del espacio y la calidad de vida. Esto es posible si se contempla la participación de los sujetos involucrados y se tiene claro que la sociedad no existe fuera del espacio, el cual adquiere así significación social y juega distintos roles en los procesos sociales. La segregación espacial es parte de los engranajes que determinan un acceso socialmente diferenciado de la población a bienes públicos o de consumo colectivo, tales como el paisaje, el medio ambiente, la seguridad ciudadana y, en general, la calidad de vida. La distribución de bienes y servicios se debe guiar bajo lógicas que favorezcan la integración de aquellos individuos menos favorecidos (Paulsen-Espinoza, 2018).

El derecho a la ciudad, nos dice Santos (2014b), es un derecho inalienable a una vida decente para todos, sin importar el lugar en que se encuentre, la ciudad o el campo, más que el derecho a la ciudad, lo que está en juego es el derecho a obtener aquellos bienes y servicios mínimos para una existencia digna, además de garantizar una relación social transversal que aproxime a los diversos sectores de la sociedad y que no imponga barreras arquitectónicas $\mathrm{y} / \mathrm{o}$ de pensamiento que marquen distanciamientos [B]

\section{Bibliografía}

Aguilar, F. (2001). Morelia. urbanización en tierra ejidal 1927-1994. México D.F.: Universidad Autónoma Metropolitana-Unidad Xochimilco.

Álvarez, A. M. y Cavieres, H. (2016). El Castillo: territorio y subjetividades de la espera. EURE, 42(125), 155-174. http://dx.doi.org/10.4067/S025071612016000100007
Ávila, P. (2014). Urbanización, poder local y conflictos ambientales en Morelia. En A. Vieyra y A. Larrazabal (Eds.), Urbanización, sociedad y ambiente. Experiencias en ciudades medias. Vol. I (pp. 121-149). Morelia: Universidad Nacional Autónoma de México y Secretaría de Medio Ambiente y Recursos Naturales.

Azuara, I. (2017). Interacción campo-ciudad en la dinámica de la sustentabilidad regional: hacia un derecho universal al hábitat ¿o a la ciudad? En M. Ramírez (Ed.), El derecho a la ciudad en la Ciudad de México. Aportes para su debate en el siglo XX (pp.195-223). Ciudad de México: Colofón. 
Banco Mundial. (1994). Vivienda un entorno propicio para el mercado habitacional. Washington: Banco Internacional de Reconstrucción y Fomento del Banco Mundial.

Blomley, N. (2016). The territory of property. Progress in Human Geography, 40(5), 593-609. https://doi.org/10.1177/0309132515596380

Borón, A., Gambina, J. y Minsburg, N. (Comps.) (2004). Tiempos violentos. Neoliberalismo, globalización y desigualdad en América Latina. Buenos Aires: CLACSO.

Bos, F. \& Jaffe, R. (2015). A rejuvenated approach to urban development and inequality: Young people's perceptions and experiences in Rio de Janeiro. Habitat International, 48, 106-112. https://doi.org/10.1016/j.habitatint.2015.03.014

Brenner, N., Peck, J. \& Theodore, N. (2010). Variegated neoliberalization: geographies, modalities, pathways. Global Networks, 10(2), 182-222. https://doi.org/10.1111/j.1471-0374.2009.00277.x

Christophers, B. (2016). Neoliberalizing Keynes? Dialogues in Human Geography, 6(2), 158-161. https://doi.org/10.1177/2043820616653018

Congreso Legislativo (2015). Dictamen que reforma, adiciona y deroga diversas disposiciones del Código de Desarrollo Urbano. Gaceta Parlamentaria, IV (144J), 01-24. http://sil.gobernacion.gob.mx/Archivos/Documentos/ 2018/10/asun 3755832 20181018 1539867746.pdf

Di Virgilio, M. y Perelman, D. (Eds.). (2014). Ciudades latinoamericanas: desigualdad, segregación y tolerancia. Buenos Aires: CLACSO.

Elwood, S., Lawson, V., \& Sheppard, E. (2017). Geographical relational poverty studies. Progress in Human Geography, 41(6), 745-765. https://doi.org/10.1177/0309132516659706

Fernández, A. (2016). Riesgos de la ciudad (digital) del futuro: control, guetización y desarraigo. Andamios, 13(32), 15-36. http://dx.doi.org/10.29092/uacm.v13i32.523

García, T. J. y Mas, J. F. (2008). Comparación de metodologías para el mapeo de la cobertura y uso del suelo en el sureste de México. Investigaciones Geográficas, 67, 7-9.
Gasca, J. (2013). Restructuración y polarización entre ciudades y regiones en México durante el neoliberalismo. En P. Olivera (Ed.), Polarización social en la ciudad contemporánea (pp. 21-53). México D.F.: Universidad Nacional Autónoma de México.

Gobierno de México (2016). México en Hábitat III. Ciudad de México: SEDATU.

Harvey, D. (2001). Espacios del capital. Hacia una geografía crítica. Madrid: Akal.

Hidalgo, R., Santana, D., Alvarado, V., Arenas, F., Salazar, A., Valdebenito, C. y Álvarez, L. (Coords.) (2016). En las costas del neoliberalismo. Naturaleza, urbanización y producción inmobiliaria: experiencias en Chile y Argentina. Santiago de Chile: Serie GEOlibros.

Hidalgo, R., Alvarado, V. y Santana, D. (2017a). La espacialidad neoliberal de la producción de vivienda social en las áreas metropolitanas de Valparaíso y Santiago (1990-2014): ¿hacia la construcción ideológica de un rostro humano? Cadernos Metrópole, 19(39), 513-535. https://doi.org/10.1590/cm.v19i39.30179

Hidalgo, R., Urbina, P., Alvarado, V. y Paulsen-Bilbao, A. (2017b). Desplazados y cंolvidados?: contradicciones respecto de la satisfacción residencial en Bajos de Mena, Puente Alto, Santiago de Chile. Revista INVI, 32(89), 85-110. http://dx.doi.org/10.4067/S0718$\underline{83582017000100085}$

Inostroza, L. (2017). Informal urban development in Latin American urban peripheries. Spatial assessment in Bogota, Lima and Santiago de Chile. Landscape and Urban Planning, 165, 267-279. https://doi.org/10.1016/j.landurbplan.2016.03.021

Klintowitz, D.C. y Rufino, M.B. (2014). A produção do programa Minha Casa Minha Vida na região metropolitana da Baixada Santista: reafirmação da configuração metropolitana e exclusão socioterritorial. Pensamento \& Realidade, 29(3), 116134.

Lungo, M. (2005). Globalización, grandes proyectos y privatización de la gestión urbana. Revista Urbano, 8(11), 18-25. 
Madaleno, I.M. y Gurovich, A. (2004). "Urban versus rural" no longer matches reality: an early public agroresidential development in periurban Santiago, Chile. Cities, 21(6), 513-526. https://doi.org/10.1016/i.cities.2004.08.001

Maricato, E. (2013). Brasil, Cidades. Alternativas para a crise urbana. Petrópolis: Vozes.

Martínez, R. y Soto, E. (2012). El Consenso de Washington: La instauración de las políticas neoliberales en América Latina. Política y Cultura, 37, 35-64.

Meller, P. (1991). Adjustment and social costs in Chile during the 1980s. World Development, 19(11), 15451561. https://doi.org/10.1016/0305-750X(91)90005-3

Méndez, Y., Vieyra, A., Güiza-Valverde, F. y Hernández Guerrero, J. (2016). Relaciones sociales y expansión urbana: aplicación del enfoque de capital social en el análisis de la adaptación de los medios de vida agropecuarios a la periurbanización. En A. Vieyra (Ed.), Procesos urbanos, pobreza y ambiente. Implicaciones en ciudades medias y megaciudades (pp. 89-107). Ciudad de México: UNAM-CIGA.

Moreno, J., Dutrénit, C. y Martin, P. (2013). Crecimiento económico, innovación y desigualdad en América Latina: Avances, retrocesos y pendientes PostConsenso de Washington. México D.F.: CEPAL.

Olivera, P. (2014). Neoliberalismo en la Ciudad de México: polarización y gentrificación. En R. Hidalgo y M. Janoschka (Eds.), La ciudad neoliberal. Gentrificación y exclusión en Santiago de Chile, Buenos Aires, Ciudad de México y Madrid (pp. 151177). Santiago: Serie GEOlibros.

Ortiz, J. y Escolano, S. (2013). Movilidad residencial del sector de renta alta del Gran Santiago (Chile): hacia el aumento de la complejidad de los patrones socioespaciales de segregación. EURE, 39(118), 77-96. http://dx.doi.org/10.4067/S025071612013000300004

Paulsen-Espinoza, A. (2018). El alcance moral de un contrato social justo para la vivienda y el derecho a la ciudad: hacia la conquista de la igualdad y la libertad. En M. Correa, F. Arenas y V. Alvarado (Eds.), Ética en Geografía. Reflexiones sobre espacios y territorios para el mundo en que estamos y el que se nos viene (pp. 23-38). Santiago de Chile: Serie GEOlibros.

Poncela, L., Vieyra, A. y Méndez, Y. (2015). Procesos participativos intramunicipales como pasos hacia la gobernanza local en territorios periurbanos. La experiencia del municipio de Tarimbaro, Michoacán, México. Journal of Latin American Geography, 14(2), 130-156. https://doi.org/10.1353/lag.2015.0027

Pradilla, E. (1994). La reforma al artículo 27 constitucional y la cuestión agraria. En VV. AA., EI articulo 27 y el desarrollo urbano (pp. 21-28). México D.F.: Cámara de Diputados-LV Legislatura.

Ramírez, J. (1989). Los objetivos de la Ley General de Asentamientos Humanos. En G. Garza (Ed.), Una década de planeación urbano-regional en México, 1978-1988 (pp. 27-53). México D.F.: Colegio de México.

Ramírez, M. (2017). El derecho a la ciudad: de sus orígenes a la recuperación actual. En M. Ramírez (Ed.) El derecho a la ciudad en la ciudad de México. Aportes para su debate en el siglo XX (pp.43-88). Ciudad de México: Colofón.

Rodríguez, N. (2017). Políticas urbanas en la ciudad de Morelia en el periodo 1998-2011. En C. Téllez y L. Mejía (Eds.), Problemas metropolitanos y buen gobierno en México (pp. 171-194). Zamora: El Colegio de Michoacán.

Sabatini, F. y Brain, I. (2008). La segregación, los guetos y la integración social urbana: mitos y claves. EURE, 34(103), 5-26. http://dx.doi.org/10.4067/S025071612008000300001

Salazar, A., Moreira-Muñoz, A., \& del Río, C. (2015). La Campana-Peñuelas biosphere reserve in Central Chile: Threats and challenges in a peri-urban transition zone. Eco.Mont, 7(1), 66-71. 10.1553/eco.mont-71 s66

Santos, M. (2014a). A natureza do espaço. Técnica e tempo. Razão e emoção. São Paulo: EDUSP.

Santos, M. (2014b). O Espaço do Cidadão. São Paulo: EDUSP.

Shelton, T., Poorthuis, A., \& Zook, M. (2015). Social media and the city: Rethinking urban socio-spatial inequality using user-generated geographic information. Landscape and Urban Planning, 142, 198-211. https://doi.org/10.1016/j.landurbplan.2015.02.020 
Springer, S. (2011). Articulated neoliberalism: the specificity of patronage, kleptocracy, and violence in Cambodia's neoliberalization. Environment and Planning A, 43(11), 2554-2570. https://doi.org/10.1068/a43402

Springer, S. (2012). Neoliberalism as discourse: between Foucauldian political economy and Marxian poststructuralism. Critical Discourse Studies, 9(2), 133-147.

https://doi.org/10.1080/17405904.2012.656375

Springer, S. (2015). Postneoliberalism? Review of Radical Political Economics, 47(1), 5-17. https://doi.org/10.1177/0486613413518724
Turner, M. D. (2017). Political ecology III : The commons and commoning. Progress in Human Geography, 41(6), 795-802. https://doi.org/10.1177/0309132516664433

Vieyra, A. (2016). Procesos urbanos pobreza y ambiente. Implicaciones en ciudades medias y megaciudades. Ciudad de México: UNAM-CIGA.

Volochko, D. (2015). Nova produção das periferias urbanas e reprodução do cotidiano. En A. Alessandri (Ed.), Crise Urbana (pp. 105-128). São Paulo: Contexto. 